\title{
Current status of bariatric surgery in Japan and effectiveness in obesity and diabetes
}

\author{
Akira Sasaki • Go Wakabayashi · Yoshikazu Yonei
}

Received: 18 January 2013/ Accepted: 14 March 2013/Published online: 18 April 2013

(C) The Author(s) 2013. This article is published with open access at Springerlink.com

\begin{abstract}
The rate of obesity in Japan, defined as having a body mass index (BMI) of $25 \mathrm{~kg} / \mathrm{m}^{2}$ or greater, is reportedly at $24 \%$, a lower level of severe obesity than in the EU and US. However, the incidence of obesity-related health problems is reportedly higher among Asians. Laparoscopic sleeve gastrectomy (LSG) is the most frequently performed bariatric surgery in Japan and accounted for $54 \%$ of such surgeries in 2011; procedures such as laparoscopic adjustable gastric banding and laparoscopic Roux-en-Y gastric bypass (LRYGB), practiced frequently worldwide, were uncommon. Possible reasons include concern over delayed postoperative discovery of gastric cancer in LRYGB, and rapid adoption of the comparatively simple LSG procedure. In type 2 diabetes mellitus (T2DM) patients, where continued pursuit of medical treatment is difficult and a potential exists for future deterioration of diabetes-complicated diseases, the criterion for surgical indication in the EU and US is a BMI of $30-35 \mathrm{~kg} / \mathrm{m}^{2}$, with priority given to $\mathrm{BMI}>35 \mathrm{~kg} / \mathrm{m}^{2}$. For Asian patients, the recommendation is to lower this indication criterion by $2.5 \mathrm{~kg} / \mathrm{m}^{2}$. Efficacy of metabolic surgery is anticipated particularly among T2DM patients with obesity complication, a short history of insulin treatment, and intact insulin secreting ability, and in these cases bariatric surgery should be contemplated.
\end{abstract}

\footnotetext{
A. Sasaki · G. Wakabayashi

Department of Surgery, Iwate Medical University School

of Medicine, Morioka, Japan

Y. Yonei $(\bowtie)$

Anti-Aging Medical Research Center, Graduate School of Life and Medical Sciences, Doshisha University, Kyoto 610-9394, Japan

e-mail: yyonei@mail.doshisha.ac.jp
}

Keywords Obesity · Diabetes mellitus ·

Bariatric surgery · Metabolic surgery · Sleeve gastrectomy · Gastric bypass

$\begin{array}{ll}\text { Abbreviations } \\ \text { WHO } & \text { World Health Organization } \\ \text { NIH } & \text { National Institutes of Health } \\ \text { IDF } & \text { International Diabetes Federation } \\ \text { JGES } & \text { Japan Gastroenterological Endoscopy Society } \\ \text { JASSO } & \text { Japan Society for the Study of Obesity } \\ \text { JELTO } & \text { Japan Research Society for Endoscopic and } \\ & \text { Laparoscopic Treatment of Obesity } \\ \text { JSSO } & \text { Japanese Society for the Surgery of Obesity and } \\ & \text { Metabolic Disorders } \\ \text { BMI } & \text { Body mass index } \\ \text { \%EWL } & \text { Percentage of excess weight loss } \\ \text { LRYGB } & \text { Laparoscopic Roux-en-Y gastric bypass } \\ \text { LAGB } & \text { Laparoscopic adjustable gastric banding } \\ \text { LSG } & \text { Laparoscopic sleeve gastrectomy } \\ \text { EIGB } & \text { Endoscopic intragastric balloon } \\ \text { BPD } & \text { Biliopancreatic diversion } \\ \text { DJB } & \text { Duodenojejunal bypass } \\ \text { T2DM } & \text { Type 2 diabetes mellitus } \\ \text { GLP-1 } & \text { Glucagon-like peptide-1 }\end{array}$

Introduction

At the 33rd Annual Session of the United Nations Standing Committee on Nutrition held in 2006, the World Health Organization (WHO) reported that nearly 300 million adults worldwide were severely obese. While the definition of obesity in the EU and US as having a body mass index (BMI) of $30 \mathrm{~kg} / \mathrm{m}^{2}$ or greater places more than one-third of the adult population within the category 
of obesity, some 6-10 million individuals are said to be severely obese, with a BMI of $40 \mathrm{~kg} / \mathrm{m}^{2}$ or greater. Based on current trends, the rate of obesity in the US is projected to reach approximately $40 \%$ by 2025 [1]. In Japan, the Japan Society for the Study of Obesity (JASSO) defines obesity as a BMI of $25 \mathrm{~kg} / \mathrm{m}^{2}$ or greater. According to recent surveys, BMI values are 25 or greater in $24 \%$ of the population, 30 or greater in $3 \%, 35$ or greater in $0.5 \%$, and 40 or greater in $0.2 \%$, reflecting a lower level of severe obesity than in the EU or US. However, a WHO Expert Committee reported that the incidence of health problems stemming from obesity is higher among Asians [2]. While the general treatment for obesity in Japan centers on medical treatments such as dietary, behavioral, and exercise therapy, surgical treatments termed "metabolic surgery" have been practiced more recently. Our review article discusses the current status of bariatric surgery in Japan and its effectiveness in the treatment of obesity and diabetes.

\section{Worldwide trends in bariatric surgery and current status in Japan}

Based on questionnaire survey results from 33 countries, Buchwald et al. [3, 4] reported that more than 340,000 bariatric surgeries were performed worldwide in 2008. The proportion of laparoscopic procedures among bariatric surgeries was $63 \%$ in 2003 but had reached $92 \%$ in 2008. Types of bariatric surgery are shown in Fig. 1. The relative shares of various procedures in 2008 included $43 \%$ laparoscopic Roux-en-Y gastric bypass (LRYGB), 42 \% laparoscopic adjustable gastric banding (LAGB), and $5 \%$ laparoscopic sleeve gastrectomy (LSG). LAGB allows adjustment of the band tightener after surgery and removal of the band in reoperation and is also a comparatively simple procedure. For these reasons, LAGB has increased rapidly in North America and is predicted to become the most frequently performed weight loss surgery in the near future.

Bariatric surgery was first performed in Japan by Kawamura et al. in 1982 [5]. The bariatric restrictive procedure became eligible for insurance reimbursement in 1988 but did not achieve widespread dissemination for reasons of technique and indication. However, the increasing number of obese patients, growing societal needs in response to obesity, and progress in laparoscopicassisted surgical techniques have produced remarkable developments in the treatment of obesity. Kitano et al. [6] introduced the endoscopic intragastric balloon (EIGB) to Japan in December 2004 and LAGB in August 2005 and have reported good results. But as of 2012, only 10 facilities are performing bariatric surgery, and currently there are few bariatric surgeons. According to the results from the 1st questionnaire survey of the Japan Research Society for Endoscopic and Laparoscopic Treatment of Obesity (JELTO), the number of bariatric surgeries performed between 2000 and 2009 was 340, while 228 procedures were performed in 2010 and 2011, showing a nascent awareness of obesity pathology and a wider discussion of indications for surgical treatment [7]. However, the most widely performed bariatric surgery in Japan is LSG, accounting for $54 \%$ in 2011, while LAGB, LRYGB, and other such procedures performed frequently worldwide are uncommon. Possible reasons include a concern over the delayed postoperative discovery of gastric cancer in LRYGB and rapid adoption of the comparatively simple LSG procedure; another issue bearing mention is consideration of the improving effect on diabetes and other obesity-related diseases.

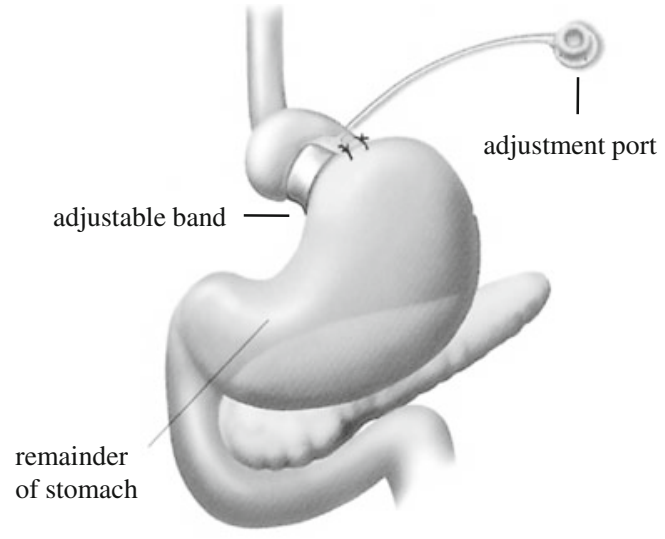

AGB

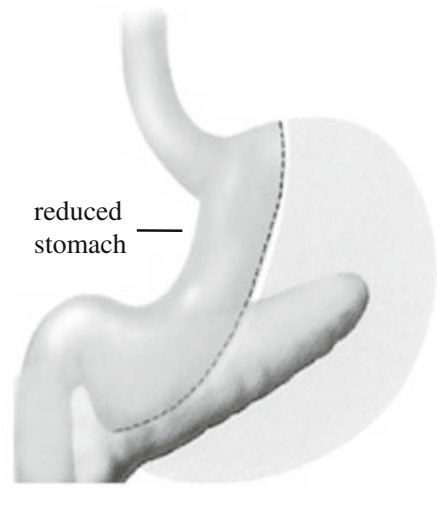

SG

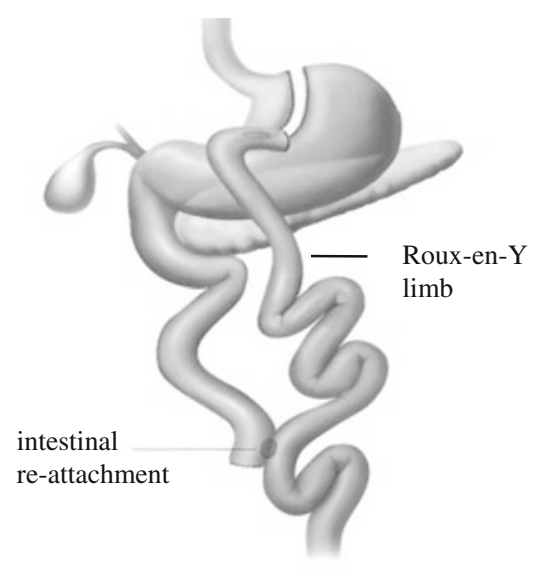

RYGB

Fig. 1 Types of bariatric surgery. $A G B$ adjustable gastric banding, $S G$ sleeve gastrectomy, $R Y G B$ Roux-en-Y gastric bypass 


\section{Indications for bariatric surgery}

The objective of treatment for obesity is to improve obesity-related diseases, without requisite attainment of a standard body weight. Medical treatments such as dietary, exercise, behavioral, and drug therapy are the treatments of first choice for obesity, but many cases of severe obesity are resistant to medical treatment and also present difficulties in achievement of adequate weight loss and maintenance of body weight after weight loss. The US National Institutes of Health (NIH) reports that more than $90 \%$ of patients on a medically managed weight loss program ultimately regain weight within 1 year. For these patients with severe obesity resistant to medical treatment, or patients in end-stage obesity syndromes that require urgent intervention for obesity-related diseases, surgical treatment must be considered. In 1991, the NIH stated that severe obesity patients (patients with a BMI of $40 \mathrm{~kg} / \mathrm{m}^{2}$ or greater, or those with a BMI of $35 \mathrm{~kg} / \mathrm{m}^{2}$ or greater and obesity-related disease) presenting a low likelihood of positive results from any treatment other than surgical treatment were indicated for bariatric surgery.

In 2006, a joint committee of the JASSO, the Japan Gastroenterological Endoscopy Society (JGES), and the Japan Society for Endoscopic Surgery created guidelines for indication of obesity treatment by endoscopy and endoscopic surgery [7]. One point of agreement was that treatments such as EIGB and LAGB were approved for use in Japan. However, the use of devices not yet medically approved in both treatments led to a policy of restricting clinical use to then-current advanced treatment hospitals. Indication of bariatric surgery was restricted to patients with a BMI of $35 \mathrm{~kg} / \mathrm{m}^{2}$ or greater and obesity-related disease resistant to medical treatment [8]. Thereafter, the Japanese Society for the Surgery of Obesity and Metabolic Disorders (JSSO) prepared a "2010 Statement for Safe and Exceptional Surgical Treatment for Severe Obesity in Japan." The statement defined surgical indication as BMI $\geq 35 \mathrm{~kg} / \mathrm{m}^{2}$ for a primary objective of weight loss and, with reference to clinical research, as BMI $\geq 32 \mathrm{~kg} / \mathrm{m}^{2}$ for a primary objective of treatment for obesity-related disease [9]. In 2011, the International Diabetes Federation (IDF) called for a BMI of $30-35 \mathrm{~kg} / \mathrm{m}^{2}$ to represent surgical indication for type 2 diabetes mellitus (T2DM) unresponsive to medical treatment, with priority to be given to BMI $>35 \mathrm{~kg} / \mathrm{m}^{2}$ [9]. Surprisingly, the IDF also released a statement recommending that this indication criterion be lowered by $2.5 \mathrm{~kg} / \mathrm{m}^{2}$ for Asian individuals [10].

In research carried out in France among more than 1,000 subjects undergoing LAGB in a 2-month period, outcomes were interpreted as successful if the percentage of excess weight loss (\%EWL) at 2 years postoperatively was $50 \%$ or greater. Results were good among patients age 40 years or younger, those with a BMI of $<50 \mathrm{~kg} / \mathrm{m}^{2}$ at initial examination, and those demonstrating a return to physical activity and changes in dietary habits. These were reported as crucial factors for indication of LAGB and prediction of weight loss effect. Good results were also reported in facilities with abundant experience including two or more weight loss surgeries in a 1-week period, and the adoption of a team treatment system was recommended [11]. Pontiroli et al. [12] stated that periodic outpatient visits were an important positive factor for prediction of LAGB outcomes, and in contrast, self-centered personality was an important negative factor. These factors are regarded as crucial for achieving successful bariatric surgery.

\section{Types of bariatric surgery and effects}

EIGB represents an endoscopic treatment (in general terms, a surgical treatment) for severe obesity. Surgical treatments are classified as restrictive procedures, in which the stomach is reduced in size to restrict food intake, malabsorptive procedures, in which nutrient absorption capacity is reduced by application of a surgical procedure to the small intestine, and procedures combining both of these techniques. Examples of restrictive procedures include LAGB and LSG, an example of a malabsorptive procedures is biliopancreatic diversion (BPD), which shortens the small intestine, through which food transits; and examples of treatments combining both a restrictive procedure and a malabsorptive procedure include LRYGB and LSG with duodenojejunal bypass (LSG/DJB). Though there are as of yet few reports of weight loss results from bariatric surgery in Japan, good weight loss outcomes equivalent to those among Europeans and Americans have been realized (Table 1) [7, 13, 14]. In contrast, rates of bariatric surgical complication are $25.3 \%$ in LRYGB, $5.1 \%$ in LAGB, $15.3 \%$ in LSG, and $15.5 \%$ in LSG/DJB. These rates are somewhat higher than those outside Japan due to a lack of quantitative experience, indicating that practiced technique and team treatment are crucial (Table 2) [15].

\section{EIGB}

EIGB as reported in 1982 involved numerous materialrelated complications, and long-term implantation was problematic. The debut of the $\mathrm{BIB}^{\circledR}\left({ }^{\circledR}\right.$ Orbera $\left.{ }^{\mathrm{TM}}\right)$ system in the US allowed 6-month implantation, leading to worldwide use. The most recent materials prepared by the manufacturer of the Orbera ${ }^{\mathrm{TM}}$ system (Allergan, Inc.) state that EIGB is optimally indicated for patients with a BMI of approximately $27-35 \mathrm{~kg} / \mathrm{m}^{2}$ [16]. EIGB is also 
Table 1 Outcomes of major bariatric procedures

\begin{tabular}{clrlll}
\hline Source & Procedure & $\begin{array}{l}\text { No. of } \\
\text { patients }\end{array}$ & $\begin{array}{l}\text { \%EWL } \\
12 \text { months }\end{array}$ & $\begin{array}{l}\text { \%EWL } \\
24 \text { months }\end{array}$ & $\begin{array}{l}\text { \% EWL } \\
36 \text { months }\end{array}$ \\
\hline JELTO & LRYGB & 147 & 76 & 77 & 74 \\
[7] & LSG & 102 & 66 & 68 & - \\
& LAGB & 55 & 43 & 58 & 55 \\
Deitei & LSG & 19,605 & 62.7 & 64.7 & 64.0 \\
et al. & & & & & \\
[13] & & & & & \\
Garb & LRYGB & 1,615 & 61.5 & 69.7 & 71.2 \\
et al. & LAGB & 5,768 & 42.6 & 50.3 & 55.2 \\
[14] & & & & &
\end{tabular}

JELTO Japan Research Society for Endoscopic and Laparoscopic Treatment of Obesity, $L R Y G B$ laparoscopic Roux-en-Y gastric bypass, $L S G$ laparoscopic sleeve gastrectomy, $L A G B$ laparoscopic adjustable gastric banding, $\% E W L$ percentage of excess weight loss

Table 2 Morbidity rates after bariatric procedure in Japan

\begin{tabular}{lllll}
\hline Morbidities & $\begin{array}{c}\text { LRYGB } \\
(n=91)\end{array}$ & $\begin{array}{l}\text { LAGB } \\
(n=59)\end{array}$ & $\begin{array}{l}\text { LSG } \\
(n=215)\end{array}$ & $\begin{array}{l}\text { LSG/DJB } \\
(n=84)\end{array}$ \\
\hline $\begin{array}{l}\text { Total (\%) } \\
\text { Intraoperative } \\
(\%)\end{array}$ & 25.3 & 5.1 & 15.3 & 15.5 \\
$\begin{array}{c}\text { Postoperative (\%) } \\
\text { Bleeding } \\
\quad \text { reoperation) }\end{array}$ & 1.1 & 0 & 0.9 & 0 \\
$\begin{array}{c}\text { Leakage } \\
\text { Anastomotic } \\
\text { stenosis }\end{array}$ & 15.4 & 1.7 & 1.9 & 3.6 \\
$\begin{array}{c}\text { Reoperation } \\
(\%)\end{array}$ & 9.9 & 5.1 & 1.9 & 1.2 \\
\hline
\end{tabular}

$L R Y G B$ laparoscopic Roux-en-Y gastric bypass, $L A G B$ laparoscopic adjustable gastric banding, $L S G$ laparoscopic sleeve gastrectomy, $L S G / D J B$ laparoscopic sleeve gastrectomy with duodenojejunal bypass

well-indicated as a preoperative treatment intended to mitigate perioperative risk in Class 2-3 obesity $\left(40>\right.$ BMI $\left.\geq 30 \mathrm{~kg} / \mathrm{m}^{2}\right)$ accompanied by severe health problems or among extremely obese patients (BMI $\geq 50 \mathrm{~kg} / \mathrm{m}^{2}$ ). EIGB is a treatment performed under gastroscopic observation in which physiological saline including 400-700 $\mathrm{ml}$ of methylene blue is injected into a gastric balloon inserted transorally as a technique to reduce gastric capacity and the amount of food intake. Removal is also possible and is accomplished by transoral endoscope, using a specialized remover kit. In Japan, the BIB $^{\circledR}$ system was introduced by Kitano et al. [6] in 2004, and Ohta et al. [17] reported the first Japanese clinical results for 21 cases in which the $\mathrm{BIB}^{\circledR}$ system was used. No serious complications were found in this research, and weight loss (17 cases) at 5 months after balloon implantation was $12 \mathrm{~kg}$, while \%EWL was $27 \%$. The improvement rate for obesity-related disease was $80 \%(8 / 10)$ in hypertension, $86 \%$ in dyslipidemia (12/14), $100 \%$ (9/9) in liver dysfunction, $100 \%(10 / 10)$ in metabolic syndrome, and $100 \%(5 / 5)$ in diabetes, reflecting good results. However, they reported that two patients $(9.5 \%)$ required early removal (within 1 week) of the balloon due to continuous abdominal discomfort. They also reported that four patients maintained a $\% \mathrm{EWL}>20$, and that the remaining four patients returned to their pretreatment weight (\%EWL at 12 months after balloon removal: $27 \pm 12$ vs $0.2 \pm 2.1$, $P<0.01$ ). Genco et al. [18] investigated 2,515 cases of intragastric balloon implantation in multicenter collaborative research and reported that \%EWL 6 months postoperatively was $34 \%$, while the rate of complications was $2.8 \%(0.76 \%$ gastric obstruction, $0.19 \%$ gastric rupture, $0.36 \%$ balloon rupture).

\section{LAGB}

LAGB is a restrictive procedure in which a silicone band is wrapped around the upper portion of the stomach and restricts food intake. An adjustable band was developed in 1986, and use in laparoscopic surgery began in 1993. Food is digested and absorbed along the physiological route. Today, a tool (Lap-Band ${ }^{\circledR}$; INAMED Co.) allowing adjustment of band tightness has been developed, and adjustment is accomplished through an access point embedded subcutaneously. Typically, the device is implanted by the pars flaccida technique (an approach from the avascular portion of the lesser omentum), and several gastric-gastric sutures are made to prevent band slippage. Benefits include the ability to adjust band tightness postoperatively, to remove the band by reoperation and return to the preoperative state, and to perform postoperative endoscopy in normal fashion. The difficulty of the surgical technique in LAGB is lower than that in LRYGB, and complications are also less frequent, leading to performance in many countries. However, the weight loss effect and the improvement rate in obesity-related diseases are slightly lower than those in LRYGB, and depending on postoperative symptoms, several band adjustments may be necessary. Surgical indication must be considered carefully.

According to a systematic review reported by Buchwald et al. [19], mean postoperative \%EWL by surgical technique was $47.5 \%$ in LAGB and $61.6 \%$ in LRYGB, reflecting significance for LRYGB versus LAGB. Similar results have also been reported in multicenter, randomized clinical research. Nguyen et al. [20] compared 86 cases of LAGB and 111 cases of LRYGB and reported that 4-year postoperative \%EWL was $45.4 \%$ in LAGB and $68.4 \%$ in LRYGB. Himpens et al. [21] compared 40 cases of LAGB 
and 40 cases of LSG and reported that the 3-year postoperative \%EWL was $48 \%$ in LAGB and $66 \%$ in LSG.

As of yet there are few reports of long-term results for LAGB in Japan. Ohta et al. [22] performed LAGB in 27 Japanese cases of severe obesity with a mean BMI of $41 \mathrm{~kg} / \mathrm{m}^{2}$ and reported that the 5-year postoperative $\%$ EWL was $56 \%$. Kasama et al. [23] performed LAGB in 13 cases of severe obesity with a mean BMI of $37.5 \mathrm{~kg} / \mathrm{m}^{2}$ and reported that 18 -month postoperative reduction of excess BMI was $69.6 \%$.

\section{LRYGB}

LRYGB is a surgical technique combining a restrictive procedure and a malabsorptive procedure, and accounted for $66 \%$ of bariatric surgeries (35\% laparoscopic surgeries, $31 \%$ laparotomies) performed worldwide in 2002 and 2003 [3]. The surgical technique entails the separation of the upper portion of the stomach with an automatic suturing device to reduce the gastric capacity by $15-30 \mathrm{ml}$. The jejunum is separated with an automatic suturing device at a location approximately $50 \mathrm{~cm}$ from the Treitz ligament, and the jejunum is lifted on the anal side and mechanically anastomosed to the contracted stomach. The length of the Roux-Y leg is approximately $75 \mathrm{~cm}$ in the standard surgical technique and approximately $150 \mathrm{~cm}$ in extremely obese patients (BMI $\geq 50 \mathrm{~kg} / \mathrm{m}^{2}$ ). The absorptive and digestive capacity of the alimentary system is thus reduced, providing an effective reduction of capacity.

At a $\% \mathrm{EWL}$ of $62 \%$, better results have been reported than in EIGB and LAGB. Improvement in obesity-related disease was $86 \%$ in diabetes, $79 \%$ in hypertension, $79 \%$ in hyperlipidemia, and $84 \%$ in sleep apnea syndrome. The rate of postoperative complications was $5 \%$, and the rate of surgical deaths was $0.5 \%$ [3]. LRYGB is the most frequently performed bariatric surgery worldwide, performed in approximately $80 \%$ of cases in the US. Adams et al. [24] investigated death rates comparatively during a mean 7.1-year observational period among 7,925 age-, sex, and BMI-matched subjects in an RYGB cohort and 7,925 subjects in a control cohort $\left(\mathrm{BMI} \geq 35 \mathrm{~kg} / \mathrm{m}^{2}\right)$. The death rate in the RYGB cohort was $40 \%$ lower than among controls. Death rates in obesity-related disease were reportedly reduced by $56 \%$ for coronary artery disease, $92 \%$ for diabetes, and $60 \%$ for cancer. However, death rates from causes unrelated to obesity such as accidents and suicide were reportedly higher than in the control cohort, making future trends in RYGB of interest. Considering that the current incidence of gastric cancer in Japan is higher than that in the EU and US, the difficulty that RYGB presents to examination of the residual stomach calls for a prudent stance on indication of RYGB in Japan.

\section{LSG}

LSG, used as an initial bariatric surgery for severely obese patients, is a new technique for lowering rates of complication and surgical death. Though its efficacy has drawn attention, it was not recommended by the 2004 American Society for Bariatric Surgery Consensus Conference on Bariatric Surgery. The surgical technique involves insertion of a 40-60 Fr esophageal bougie into the stomach and gastric excision with an automatic suturing device from the greater curvature of the pyloric portion, approximately $5 \mathrm{~cm}$ proximally from the pyloric ring, toward the angle of His. The intent is to reduce gastric capacity to $60-200 \mathrm{ml}$, and if a sufficient capacity-reducing effect is not achieved, a secondary RYGB or other such treatment is pursued.

For this new surgical technique, further study of longterm results is needed, but 19,605 cases of LSG were investigated at the Third International Summit for LSG held in 2010. Overweight reduction rates at 1, 2, 3, 4, and 5 years postoperatively were $62.7,64.7,64.0,57.3$, and $60.0 \%$, respectively [13]. Reported complications were $1.3 \%$ high leaks, $0.5 \%$ lower leaks, and a $0.1 \%$ rate of death, and the surgical technique was evaluated as safe. From studies in Asia, Moon Han et al. [25] reported a good weight reduction of $72 \%$ mean $\%$ EWL at 6 months postoperatively and $83 \%$ at 1 year in short-term results for 130 cases of LSG among obese patients with a mean BMI of $37.2 \mathrm{~kg} / \mathrm{m}^{2}$. Sasaki et al. [26] reported good results for median \%EWL, at $56(42-70) \%$ at 6 months postoperatively, and 68 (49-87) \% at 1 year in short-term results for seven LSG cases among severe obesity patients with a median BMI of $47 \mathrm{~kg} / \mathrm{m}^{2}$. Tagaya et al. [27] investigated short-term results comparatively in 30 cases among obese patients with a mean BMI of $49.1 \mathrm{~kg} / \mathrm{m}^{2}$, comparing results for BMI of $<50 \mathrm{~kg} / \mathrm{m}^{2}$ and BMI of $\geq 50 \mathrm{~kg} / \mathrm{m}^{2}$. They reported good results for patients with BMI of $<50 \mathrm{~kg} / \mathrm{m}^{2}$, i.e., mean BMI of 27.8 versus $52.2 \mathrm{~kg} / \mathrm{m}^{2}$, at 12 months postoperatively and 29.7 versus $45.5 \mathrm{~kg} / \mathrm{m}^{2}$ at 18 months postoperatively. These reports show that LSG alone has the potential to produce good results among Asian patients with severe obesity represented by a BMI of $<50 \mathrm{~kg} / \mathrm{m}^{2}$, and given that the procedure does not use specialized devices awaiting medical approval, further adoption is anticipated.

\section{Improvement of obesity-related disease}

The objective of bariatric surgery is not weight loss alone, but also improvement of prognosis in obesity-related disease. Sjöström et al. [28] compared long-term results prospectively among 2,010 cases undergoing weight loss surgery and a medically treated control cohort of 2,037 
cases matched on 18 indices, including sex, age, and body weight. In the control cohort, no long-term weight loss effect was observed, while in the surgical cohort, change in body weight plateaued at approximately 10 years postoperatively, after which the weight loss effect was maintained. This study reported that the effect on survival rates from weight reduction and improvement of obesity-related diseases was a $29 \%$ reduced risk of death in the surgical cohort versus controls.

Weight loss surgery has an improving effect on obesityrelated disease additional to that of body weight reduction and has more recently been termed "metabolic surgery". RYGB has a reportedly greater improvement effect on diabetes than food intake restriction surgery. Though the mechanism is not understood, two current theories exist. In one, the "hindgut hypothesis", bypass of the upper small intestine diverts food directly to the lower small intestine, where glucagon-like peptide-1 (GLP-1) secretory cells exist, thus promoting GLP-1 secretion. In another, the "foregut hypothesis", an as-yet unknown glucose tolerance complicating factor which inhibits GLP-1 secretion is secreted from the upper small intestine, and because bypass surgery prevents food from passing through the upper small intestine, this factor is no longer secreted [29].

Hutter et al. [30] reported that remission or improvement rates on T2DM were $79 \%$ in LRYGB and $55 \%$ in LSG, and outside Japan, there are many reports of better results in LRYGB versus LSG. In Japan, however, LSG, though a restrictive procedure, has been shown to have an improving effect on diabetes rivaling that of LRYGB. In a JELTO report, Ohta et al. [7] reported good results for remission of T2DM (fasting glucose $<110 \mathrm{mg} / \mathrm{dl}$ and $\mathrm{HbA} 1 \mathrm{c}<6 \%$ without medication) from LSG, specifically, $91 \%$ in LSG, $88 \%$ in LRYGB, and $63 \%$ in LAGB (Table 3). Sasaki [31] also reported achievement of complete remission (fasting glucose $<100 \mathrm{mg} / \mathrm{dl}$ and $\mathrm{HbA} 1 \mathrm{c}$

Table 3 Remission and improvement rates of T2DM

\begin{tabular}{llcl}
\hline Source & Procedure & No. of patients & Remission (\%) \\
\hline JELTO [7] & LRYGB & 64 & 88 \\
& LSG & 35 & 91 \\
& LAGB & 19 & 63 \\
Buchwald et al. [19] & LRYGB & 989 & 83.8 \\
& LAGB & 205 & 47.8 \\
Hutter et al. [30] & LRYGB & 4,452 & $79^{\mathrm{a}}$ \\
& LSG & 249 & $55^{\mathrm{a}}$ \\
& LAGB & 2,558 & $44^{\mathrm{a}}$
\end{tabular}

T2DM type 2 diabetes mellitus, JELTO Japan Research Society for Endoscopic and Laparoscopic Treatment of Obesity, LRYGB laparoscopic Roux-en-Y gastric bypass, $L S G$ laparoscopic sleeve gastrectomy, $L A G B$ laparoscopic adjustable gastric banding

${ }^{\text {a }}$ Remission and improvement rates
$<5.8 \%$ without medication) among seven T2DM patients after LSG. Though the mechanism of improved glucose tolerance after LSG is unknown, increased secretion of GLP-1 after surgery has been observed, as reported in LRYGB [31]. Lee et al. [32] reported metabolic surgery results in 200 cases of T2DM with a BMI of $<35 \mathrm{~kg} / \mathrm{m}^{2}$ in Taiwan, South Korea, India, Japan, and Hong Kong. Remission rates for T2DM were high in cases of gastric bypass surgery with a $<5$-year treatment history, BMI of $30-35 \mathrm{~kg} / \mathrm{m}^{2}$, and $3 \mathrm{ng} / \mathrm{ml}$ or higher C-peptide. Kasama et al. [33] also reported rapid improvement in glucose tolerance over a period of several months and achievement of complete remission in $91 \%$ of cases when LSG/DJB was performed. These results were realized primarily among patients with severe T2DM receiving insulin and manifesting low C-peptide levels, reduced initial insulin secreting capacity in oral glucose load testing, kidney disease, retinopathy, neuropathy, and other microangial complications. This indicates that even simple LSG and similar surgical procedures can provide remission of T2DM in attempts to reduce body weight by restriction of caloric intake among Japanese T2DM patients whose essential pathology is regarded as insulin resistance in conjunction with excess fat storage. At the same time, bypass-based surgical procedures acting directly on insulin secretion, combined with weight loss, are deemed to have an ample antidiabetic effect among T2DM patients whose essential pathology is regarded as impaired insulin secretion.

\section{Conclusion}

The principles of obesity treatment are based on the medical treatments of dietary and exercise therapy, which, combined with behavioral therapy allowing long-term maintenance, improve lifestyle habits. For patients with a BMI of $35 \mathrm{~kg} / \mathrm{m}^{2}$ or greater and obesity-related disease resistant to medical treatment, bariatric surgery must be considered, and its outcomes among Japanese individuals are good, as in cases outside Japan. LRYGB and LSG also offer increased GLP-1 secretion postoperatively, suggesting a large potential for treatment of T2DM patients; however, the associated mechanisms are unknown, and further clinical research is needed. Bariatric surgery, which offers the effects of metabolic surgery, should be considered for T2DM patients with difficulty in continuing medical treatment and a potential for future deterioration and diabetic complications. Bariatric surgery is particularly well-indicated for T2DM patients with obesity complications, a short insulin treatment history, and intact insulin secreting ability. From the medical economics perspective of obesity and metabolic syndrome as well, minimally 
invasive bariatric surgery has substantial promise, and insurance coverage in the near term is awaited.

Conflict of interest The authors declare that they have no conflict of interest.

Open Access This article is distributed under the terms of the Creative Commons Attribution Noncommercial License which permits any noncommercial use, distribution, and reproduction in any medium, provided the original author(s) and the source are credited. The exclusive right to any commercial use of the article is with Springer.

\section{References}

1. Kopelman PG. Obesity as a medical problem. Nature. 2000;404:635-43.

2. Choo V. WHO reassesses appropriate body-mass index for Asian populations. Lancet. 2001;360:235.

3. Buchwald H. Bariatric surgery for morbid obesity: health implications for patients, health professionals, and third-party payers. J Am Coll Surg. 2005;200:593-603.

4. Buchwald H, Oien DM. Metabolic/bariatric surgery worldwide 2008. Obes Surg. 2009;19:1605-11.

5. Kasama K. Dr. Isao Kawamura, a pioneer in morbid obesity treatment in Japan. Obes Surg. 2012;22:1143.

6. Kitano S, Shiromizu A, Endo Y, Ohta M, Yoshimatsu H. Intragastric balloon therapy for the treatment-resistant obesity (in Japanese). Gastroenterol Endosc. 2005;47:2197-201.

7. Ohta M, Kitano S, Kasama K, Kawamura I, Inamine S, Wakabayashi $\mathrm{G}$, et al. Results of a national survey on laparoscopic bariatric surgery in Japan, 2000-2009. Asian J Endosc Surg. 2011:4:138-42.

8. Japan Society for Endoscopic Surgery. Statement on surgical treatments for morbid obesity (in Japanese). http://www.asas.or. $\mathrm{jp} / \mathrm{jses} / \mathrm{kitei} / \mathrm{himan} . \mathrm{html}$.

9. Japanese Society for the Surgery of Obesity and Metabolic Disorder. Statement on safety and excellent surgical treatments for morbid obesity in Japan (in Japanese). http://plaza.umin.ne. jp/ jsto/gakujyutsu/index.html.

10. Dixon JB, Zimmet P, Alberti KG, Rubino F, International Diabetes Federation Taskforce on Epidemiology and Prevention. Bariatric surgery: an IDF statement for obese Type 2 diabetes. Diabet Med. 2011;28:628-42.

11. Chevallier JM, Paita M, Rodde-Dunet MH, Marty M, Nogues F, Slim K, et al. Predictive factors of outcome after gastric banding: a nationwide survey on the role of center activity and patients' behavior. Ann Surg. 2007;246:1034-9.

12. Pontiroli AE, Fossati A, Vedani P, Fiorilli M, Folli F, Paganelli $\mathrm{M}$, et al. Post-surgery adherence to scheduled visits and compliance, more than personality disorders, predict outcome of bariatric restrictive surgery in morbidly obese patients. Obes Surg. 2007;17:1492-7.

13. Deitei M, Gagner M, Erickson AL, Crosby RD. Third international summit: current status of sleeve gastrectomy. Surg Obes Relat Dis. 2011;7:749-59.

14. Garb J, Welch G, Zagarine S, Kuhn J, Romanelli J. Bariatric surgery for the treatment of morbid obesity: a meta-analysis of weight loss outcomes for laparoscopic adjustable gastric banding and laparoscopic gastric bypass. Obes Surg. 2009;19:1447-55.

15. Finks JF, Kole KL, Yenumula PR, English WJ, Krause KR, Carlin AM, et al. Predicting risk for serious complications with bariatric surgery: results from the Michigan bariatric surgery collaborative. Ann Surg. 2011;254:633-40.

16. Cobourn C, Cohen L, Genco A, Lope-Nava G, Caetano Marchesini J, Wahlen $\mathrm{C}$, et al. Expert approaches to weight loss management, Issue 1 . The Allergan Orbera ${ }^{\mathrm{TM}}$ managed weight loss system.

17. Ohta M, Kitano S, Kai S, Shiromizu A, Eguchi H, Endo Y, Masaki T, Kakuma T, Yoshimatsu H. Initial Japanese experience with intragastric balloon placement. Obes Surg. 2009;19:791-5.

18. Genco A, Bruni T, Doldi SB, Forestieri P, Marino M, Busetto L, et al. BioEnterics intragastric balloon: the Italian experience with 2,515 patients. Obes Surg. 2005; 15:1161-4.

19. Buchwald H, Avidor Y, Braunwald E, Jensen MD, Pories W, Fahrbach K, et al. Bariatric surgery: a systematic review and meta-analysis. JAMA. 2004;292:1724-37.

20. Nguyen NT, Slone JA, Nguyen XM, Hartman JS, Hoyt DB. A prospective randomized trial of laparoscopic gastric bypass versus laparoscopic adjustable gastric banding for the treatment of morbid obesity: outcomes, quality of life, and costs. Ann Surg. 2009;250:631-41.

21. Himpens J, Dapri G, Cadiere GB. A prospective randomized study between laparoscopic gastric banding and laparoscopic isolated sleeve gastrectomy: results after 1 and 3 years. Obes Surg. 2006;16:1450-6.

22. Ohta M, Kitano S, Kai S, Shiromizu A, Iwashita Y, Endo Y, et al. Initial Japanese experience with the LAP-BAND system. Asian J Endosc Surg. 2013;6:39-43.

23. Kasama K, Tagaya N, Kanahira E, Umezawa A, Kurosaki T, Oshiro T, et al. Has laparoscopic bariatric surgery been accepted in Japan? The experience of a single surgeon. Obes Surg. 2008;18:1473-8.

24. Adams TD, Gress RE, Smith SC, Halverson RC, Simper SC, Rosamond WD, et al. Long-term mortality after gastric bypass surgery. N Engl J Med. 2007;357:753-61.

25. Moon Han S, Kim WW, Oh JH. Results of laparoscopic sleeve gastrectomy (LSG) at 1 year in morbidly obese Korean patients. Obes Surg. 2005;15:1469-75.

26. Sasaki A, Umemura A, Nishizuka S, Nakajima J, Uesugi N, Wakabayashi G. Results of laparoscopic sleeve gastrectomy as a single stage bariatric procedure in Japanese patients. Asian J Endosc Surg. 2010;3:180-4.

27. Tagaya N, Kasama K, Kikkawa R, Kanahira E, Umezawa A, Oshiro T, et al. Experience with laparoscopic sleeve gastrectomy for morbid versus super morbid obesity. Obes Surg. 2009;19:1371-6.

28. Sjöström L, Narbo K, Sjöström CD, Karason K, Larsson B, Wedel $\mathrm{H}$, et al. Effects of bariatric surgery on mortality in Swedish obese subjects. N Engl J Med. 2007;357:741-52.

29. Knop FK. Resolution of type 2 diabetes following gastric bypass surgery: involvement of gut-derived glucagon and glucagonotropic signalling? Diabetologia. 2009;52:2270-6.

30. Hutter MM, Schirmer BD, Jones DB, Ko CY, Cohen MK, Merkow RP, et al. First report from the American College Surgeons Bariatric Surgery Center Network: laparoscopic sleeve gastrectomy has morbidity and effectiveness positioned between the band and the bypass. Ann Surg. 2011;254:410-22.

31. Sasaki A. Metabolic surgery. In: Advances in diabetology, the 46th annual postgraduate course (in Japanese). Tokyo; 2012. p. 59-64.

32. Lee WJ, Hur KY, Lakadawaia M, Kasama K, Wong SK, Lee YC. Gastrointestinal metabolic surgery for the treatment of diabetic patients: a multi-institutional international study. J Gastrointest Surg. 2012;16:45-51.

33. Kasama K, Tagaya N, Kanehura E, Oshiro T, Seki Y, Kinouchi $\mathrm{M}$, et al. Laparoscopic sleeve gastrectomy with duodenojejunal bypass: technique and preliminary results. Obes Surg. 2009;19:1341-5. 